\title{
PLANEJAMENTO PARTICIPATIVO: o plano nacional de educação como arena de conflitos e interesse
}

\author{
Luciene Amaral da Silva ${ }^{1}$ \\ Inalda Maria dos Santos²
}

\begin{abstract}
RESUMO
O artigo faz parte de uma pesquisa que buscou analisar os percalços travados na trajetória de elaboração do Plano Nacional de Educação por meio da observação da presença da participação da sociedade no planejamento de políticas públicas educacionais. Para isso, fora realizada a análise documental a partir da materialização dos documentos buscando localizar na estrutura como a temática da participação foi apresentada pelos formuladores de políticas públicas e que concepção de participação é defendida pelo governo. A pesquisa apontou que o formato atual de participação da sociedade encontra-se fragilizado por falta de condições que preparem a sociedade para atuar de forma eficaz.
\end{abstract}

Palavras-chave: Planejamento Participativo. Plano Nacional. Política Pública. Conflitos de Interesse.

\section{PARTICIPATORY PLANNING: the national plan of education as an arena of conflicts of interest}

\begin{abstract}
The article is part of a research that sought to analyze the obstacles encountered in the development of the National Education Plan based on the observation of the presence of society's participation in the planning of educational public policies. For this, a document analysis was carried out based on the materialization of the documents, seeking to locate in the structure how the theme of participation was presented by the formulators of public policies and which conception of participation is defended by the government. The research pointed out that the current participation format of society is weakened by the lack of conditions that prepare society to act effectively.
\end{abstract}

Keywords: Participatory Planning. National Plan. Public policy. Interest conflicts.

\footnotetext{
1 Doutora em Educação. Professora de Educação Básica, SEDUC/AL, Santana do Ipanema, Alagoas, Brasil. Orcid iD: https://orcid.org/0000-0002-5582-2787. E-mail: cieneamaral@hotmail.com

2 Pós-Doutora em Educação. Professora do Centro de Educação no Curso de Pedagogia e no Programa de Pós-Graduação em Educação da Universidade Federal de Alagoas, Maceió, Alagoas, Brasil. Orcid iD: https://orcid.org/0000-0002-5520-2668. E-mail: inaldasantos@vol.com.br
} 


\section{PLANIFICACIÓN PARTICIPATIVA: el plan nacional de educación como arena}

\section{de conflictos de interés}

\section{RESUMÉN}

El artículo es parte de una investigación que buscó analizar los obstáculos encontrados en el desarrollo del Plan Nacional de Educación a partir de la observación de la presencia de la participación de la sociedad en la planificación de las políticas públicas educativas. Para ello, se realizó un análisis documental a partir de la materialización de los documentos, buscando ubicar en la estructura cómo el tema de participación fue presentado por los formuladores de políticas públicas y qué concepción de participación defiende el gobierno. La investigación señaló que el formato actual de participación de la sociedad se ve debilitado por la falta de condiciones que preparen a la sociedad para actuar con eficacia.

Palabras clave: Planificación participativa. Plan Nacional. Política pública. Conflictos de intereses.

\section{INTRODUÇÃO}

O planejamento participativo ganha visibilidade no cenário político como um instrumento de representação da vontade coletiva da sociedade em busca de mudança da realidade vivida. $\bigcirc$ planejamento participativo "[...] foi desenvolvido para instituições, grupos e movimentos que não têm como primeira tarefa ou missão aumentar o lucro, competir e sobreviver, mas contribuir para a construção da realidade social" (GANDIN, 2001, p. 82).

O autor descreve três níveis de participação que, dependendo da intenção de quem está no controle da orientação, podem ser usados de forma contrária ao que preconiza a orientação social que seria a colaboração, decisão e construção em conjunto.

O primeiro nível é o da colaboração "[...] em que a autoridade chama as pessoas a trazerem sua contribuição para o alcance do que esta mesma autoridade decidiu como proposta" (GANDIN, 2001, p. 89).

O segundo nível chamado de nível de decisão, o autor sinaliza para o fato de o sujeito ter que decidir com base nas ordens que recebeu para decidir, ou seja, geralmente essas decisões são de caráter menor e muitas vezes estão desvinculadas da proposta maior.

No terceiro nível o da construção em conjunto, o autor considera o nível mais difícil de existir porque "as estruturas existentes normalmente dificultam 
esse tipo de participação, mesmo quando as pessoas, inclusive os governantes e os chefes, a desejem" (GANDIN, 2001, p. 89). Na participação, com base na construção em conjunto, o poder está nas mãos das pessoas, assim teriam condições de participar das ações com a finalidade de modificação da realidade.

Para a sociedade poder participar das decisões políticas precisa de condições necessárias para o exercício dessa participação. Benevides (2009) aponta que na preparação do sujeito e do ambiente para esse exercício, não basta falar em participação consciente se não deixar claro quais as condições que levariam o sujeito a ter essa consciência.

A necessidade de participação da sociedade tornou-se um degrau para que as políticas educacionais contemplem as diversas realidades e sejam um projeto que possibilite a igualdade entre as classes, o que não seria possível dentro do sistema capitalista.

O plano teve seus trabalhos iniciados em 1997, após a aprovação da LDB de 1996, só vindo a ser aprovado apenas em 09 de janeiro de 2001. E nele, mais uma vez, as necessidades da sociedade não foram consideradas e o texto, que ficou extenso, dizia muito em seu conteúdo.

Assim, a pesquisa fez uma análise de como se deu a elaboração do Plano Nacional de Educação e como a sociedade, representada pelo Fórum Municipal de Educação atuou nessa elaboração.

\section{A ELABORAÇÃO DO PLANO NACIONAL DE EDUCAÇÃO (2001-2010): UMA DÉCADA MARCADA PELA MERA INTENCIONALIDADE}

A história da educação no Brasil, em especial a tentativa de organizar a educação nacional através do Sistema Nacional de Educação, traz na elaboração dos planos de educação todos os percalços em que a educação passou desde o manifesto aos dias atuais conforme mostra o quadro síntese a seguir: 
Quadro 1 - Trajetória do Plano Nacional de Educação

\begin{tabular}{|c|l|}
\hline Ano & \multicolumn{1}{|c|}{ Fatos ocorridos na história da educação } \\
\hline 1932 & $\begin{array}{l}\text { Manifesto dos pioneiros, momento em que enuncia diretrizes } \\
\text { fundamentais e contribui com a formulação de um Plano de } \\
\text { reconstrução Educacional. }\end{array}$ \\
\hline 1934 & $\begin{array}{l}\text { Estabelece alínea a do artigo 150, como competência da União "fixar o } \\
\text { Plano Nacional de Educação". Prevendo, no artigo 152, um Conselho } \\
\text { Nacional de Educação (CNE). }\end{array}$ \\
\hline 1936 & $\begin{array}{l}\text { Reorganizado o Conselho Nacional de Ensino criado em 1931, passando } \\
\text { a vigorar em 1937. "Entregando este documento para Ministro da } \\
\text { Educação, denominado como 'Plano de Educação Nacional". } \\
\text { Encaminhado à câmara, o referido plano não foi aprovado. Caindo no } \\
\text { esquecimento. }\end{array}$ \\
\hline 1959 & $\begin{array}{l}\text { Crítica de Anísio Teixeira antes da aprovação do Plano, o argumento do } \\
\text { referido autor, era que a divisão dos recursos em partes iguais só iludia. } \\
\text { Pois o número de alunos da educação primária, média e superior era } \\
\text { relativamente desproporcional. Sendo ele designado a ser relator do } \\
\text { Plano. Arquitetando assim, uma fórmula matemática para a solução do } \\
\text { problema. }\end{array}$ \\
\hline 1964 & $\begin{array}{l}\text { Momento do Regime Militar, transferência dos educadores para os } \\
\text { tecnocratas, outrora subordinado ao Ministério da Educação. }\end{array}$ \\
\hline 1985 & $\begin{array}{l}\text { Eleição de Tancredo Neves para a Presidência da República, período } \\
\text { marcado pela "Nova República". }\end{array}$ \\
\hline 1993 & $\begin{array}{l}\text { No contexto da Nova República foi editado o Plano Decenal de } \\
\text { Educação para todos. Este plano não saiu do papel. }\end{array}$ \\
\hline 2001 & $\begin{array}{l}\text { Aprovada em 9 de janeiro de 2001, a Lei no 10.172, que institui o Plano } \\
\text { Nacional de Educação com vigência de 10 anos. }\end{array}$ \\
\hline 2014 & $\begin{array}{l}\text { No dia 25 de julho de 2014 foi sancionada pela Presidenta Dilma Rousseff } \\
\text { a lei no 13.005 tendo como ementa Aprova o Plano Nacional de } \\
\text { Educação - PNE e dá outras providências. }\end{array}$ \\
\hline $\begin{array}{l}\text { Prazo para que Distrito Federal, Estados e Municípios elaborem os seus } \\
\text { Planos Municipais de Educação. }\end{array}$ \\
\hline
\end{tabular}

Fonte: Teodora, Costa, Bueno, Nagel (2016).

Após o período de redemocratização do país, a partir da aprovação da Constituição Federal de 1988, a ideia de um Plano Nacional de Educação ganhou força na luta pela organização da educação brasileira. Não há dúvida de que o que impulsionou a elaboração e aprovação do Plano Nacional de Educação para a vigência de 2001 a 2010, além do art. 214 da Constituição Federal, foi a aprovação da Lei de Diretrizes e Bases da Educação Nacional - LDB, sob número 9.394 de 1996.

Os planos decenais de educação buscavam ser uma política de Estado e não uma política de governo, e por isso são influenciados com a descontinuidade de governos na execução e acompanhamento de metas e estratégias. 
Bruel $(2012$, p. 48) afirma que essa falta de continuidade das políticas "[...] tem suas origens marcadas pela falta de compreensão da política educacional como uma política de Estado, que leva sua realização a ser vista como ações de governos específicos".

O Plano Nacional de Educação 2001-2010, como um projeto para dez anos, ficou suscetível a ações fragmentadas por parte das mudanças de governo em todas as esferas políticas. No entanto, essa descontinuidade acabou por desarticular e fragilizar a política de planejamento educacional no Brasil. A elaboração de um Plano Nacional voltado para a educação deveria estar articulada com todos os entes federados para que suas propostas pudessem ser realizadas por todos.

Nesse sentido, o PNE 2001-2010 surge como efetivação da política de Estado para a educação com o objetivo de ultrapassar os planos de governo que sofreram interferência sempre que havia mudança da gestão administrativa de um governo no decorrer da história dos planos ${ }^{3}$. Depois da aprovação da atual LDB em dezembro em 1996, deixando explícito no parágrafo I, do art. 87, que após um ano de sua aprovação deveria ser encaminhado para aprovação o PNE, o plano foi iniciado apenas na segunda metade de 1997.

Foram elaboradas duas propostas do PNE para 2001-2010, uma proposta da sociedade a partir do Fórum Nacional em Defesa da Escola Pública em 1996 e outra do governo, elaborada em 1997. A proposta da sociedade, encabeçada por algumas instituições, dentre elas, a Associação Nacional de Educação (ANDE), Associação Nacional pela Formação dos Profissionais da Educação (ANFOPE), Confederação Nacional dos Trabalhadores em Educação (CNTE), dentre outras instituições que se organizaram no Fórum, buscava uma educação de qualidade e igualitária.

Valente e Romano (2002) fazem um comparativo das ideias definidas como as diretrizes gerais do plano proposto pela sociedade no projeto de lei

\footnotetext{
3 No munícipio de análise da pesquisa o plano foi elaborado no final de uma gestão de governo municipal e teve o início da vigência no mandado de outra gestão governamental, período de transição, onde acontece muitas mudanças de equipe de governo.
} 
$n^{\circ} 4.155 / 1998$, de autoria do deputado Ivan Valente do Partido dos Trabalhadores de São Paulo, transformado na Lei Ordinária n 10.172/2001 e o que consta no plano. O quadro a seguir apresenta a diferença entre as duas propostas ainda presentes no item 2 que compõe a introdução do PNE aprovado.

Quadro 2 - Reivindicações PNE da Sociedade Brasileira x PNE Aprovado

\begin{tabular}{|c|c|}
\hline $\begin{array}{l}\text { PNE da sociedade brasileira diretrizes } \\
\text { gerais }\end{array}$ & $\begin{array}{l}\text { PNE aprovado/Lei 10.172/2001 - item } 2 \text {, } \\
\text { objetivos e prioridades }\end{array}$ \\
\hline $\begin{array}{l}\text { Consolidar um Sistema Nacional de } \\
\text { Educação }\end{array}$ & $\begin{array}{l}\text { Não trata do tema (em verdade opõe-se a } \\
\text { esse instrumento). }\end{array}$ \\
\hline $\begin{array}{l}\text { Assegurar os recursos públicos } \\
\text { necessários à superação do atraso } \\
\text { educacional e ao pagamento da } \\
\text { dívida social, bem como à } \\
\text { manutenção e ao desenvolvimento } \\
\text { da educação escolar em todos os } \\
\text { níveis e modalidades, em todos os } \\
\text { sistemas de educação. Assegurar a } \\
\text { autonomia das escolas e } \\
\text { universidades na elaboração do } \\
\text { projeto político-pedagógico de } \\
\text { acordo com as características e } \\
\text { necessidades da comunidade, com } \\
\text { financiamento público e gestão } \\
\text { democrática, na perspectiva da } \\
\text { consolidação do sistema Nacional } \\
\text { de Educação }\end{array}$ & $\begin{array}{l}\text { Redução das desigualdades sociais e } \\
\text { regionais no tocante ao acesso e à } \\
\text { permanência, com sucesso, na educação } \\
\text { pública. }\end{array}$ \\
\hline $\begin{array}{l}\text { Garantir a educação pública, } \\
\text { gratuita e de qualidade para } \\
\text { crianças, jovens e adultos com } \\
\text { necessidades educacionais } \\
\text { especiais, aparelhando as unidades } \\
\text { escolares, adequando-lhes os } \\
\text { espaços, alocando-lhes recursos } \\
\text { humanos suficientes e devidamente } \\
\text { qualificados, em todos os sistemas } \\
\text { públicos regulares de educação e } \\
\text { em todos os níveis e modalidades de } \\
\text { ensino }\end{array}$ & Não trata do tema em nível de prioridade. \\
\hline $\begin{array}{l}\text { Definir a erradicação do } \\
\text { analfabetismo como política } \\
\text { permanente - e não como conjunto } \\
\text { de ações pontuais, esporádicas, de } \\
\text { caráter compensatório - utilizando, } \\
\text { para tanto, todos os recursos }\end{array}$ & $\begin{array}{l}\text { Garantia de Ensino Fundamental a todos os } \\
\text { que a ele não tiveram acesso na idade } \\
\text { própria ou que não o concluíram. A } \\
\text { erradicação do analfabetismo faz parte } \\
\text { dessa prioridade, considerando-se a } \\
\text { educação de jovens e adultos como ponto }\end{array}$ \\
\hline
\end{tabular}




\begin{tabular}{|l|l|}
\hline $\begin{array}{l}\text { disponíveis do Poder Público, das } \\
\text { universidades, das entidades e partida e parte intrínseca desse nível de } \\
\text { organizações da sociedade civil }\end{array}$ & $\begin{array}{l}\text { de pano. } \\
\text { ensino. }\end{array}$ \\
\hline $\begin{array}{l}\text { Garantir a organização de currículos } \\
\text { que assegurem a identidade do } \\
\text { povo brasileiro, o desenvolvimento }\end{array}$ & \\
da cidadania, as diversidades & \\
regionais, étnicas, culturais, & \\
articuladas pelo Sistema Nacional de & Não trata do tema em nível de prioridade. \\
Educação. Incluindo, nos currículos, \\
temas específicos da história, da \\
cultura, das manifestações artísticas, \\
científicas, religiosas e de resistência \\
da raça negra, dos povos indígenas, \\
e dos trabalhadores rurais e suas \\
influências e contribuições para a \\
sociedade e a educação brasileiras
\end{tabular}

Fonte: Valente e Romano (2002, p.105-106).

Nessa perspectiva os dois planos tinham algo em comum, a visão divergente de educação e de política educacional. Entretanto, a proposta do governo, elaborada a convite pelo Conselho Nacional de Educação CNE, o Conselho Nacional de Secretários de Educação - CONSED e a União Nacional dos Dirigentes Municipais de Educação - UNDIME. Essa proposta foi suficiente para a organização da educação por meio de metas que garantissem uma educação que elevasse o nível de desempenho dos alunos, tão bem referenciada na meta 26 do ensino fundamental e meta 3 do ensino médio, como meio de garantir uma educação de qualidade na perspectiva do governo, estabelecendo padrões de qualidade a partir da lógica mercadológica imposta por grupos econômicos (GADOTTI, 2008).

O curto prazo de tempo estipulado pela LDB de 1996 para a construção do Plano não esperava um debate intenso em todo o país, contou com uma participação pequena da sociedade (SAVIANI, 1998). O que houve, então, foram discussões desses conselhos convocados pelo Ministério da Educação e Cultura para que a estrutura do documento fosse elaborada com base no diagnóstico da realidade educacional do país levantada pelos mesmos agentes do governo. 
Isso significa que a realidade educacional foi diagnosticada a partir da perspectiva do governo, excluindo de forma clara a presença da sociedade e a análise de uma realidade diferente da apresentada pelo plano aprovado. O documento do PNE para 2001-2010 foi estruturado em três fases "1. Diagnóstico da situação; 2. Enunciado das diretrizes a serem seguidas; 3. Formulação dos objetivos e metas a serem atingidos progressivamente durante o período de duração do plano (SAVIANI, 2007, p. 1239).

O planejamento segue de forma hierárquica, os que executam não participam da elaboração ou participam de forma ínfima. Quem formula a política, geralmente, está subordinado ao projeto de sociedade governamental.

Nessa direção, a Lei n 10.172, de 9 de janeiro de 2001, que aprovou o Plano Nacional de Educação, teve como maior dificuldade a limitação orçamentária a partir dos nove vetos relacionados ao financiamento educacional, revelando a possibilidade do plano não passar apenas de uma carta de intenção composta de 296 objetivos que acumulou, em seu fracasso, também, a falta de foco.

O plano foi considerado natimorto pela inviabilidade de execução e escassez de recursos destinados para o desenvolvimento das ações. O plano precisava da destinação de $7 \%$ do Produto Interno Bruto - PIB, mas fora vetado pelo presidente Fernando Henrique Cardoso (PSDB). Acreditava-se que esse quadro poderia mudar com a entrada de outro governo. Nesse período iniciava o governo Lula da Silva (PT). Porém, na realidade, também não se destinou o percentual necessário. A ideia inicial era que fossem destinados $10 \%$ do Produto Interno Bruto - PIB, ficando acordado no congresso um progressivo aumento o que de fato não aconteceu.

De acordo com os cálculos, seria necessário o dobro de percentual para garantir o aumento da matrícula e realizar a correção das condições de trabalho e salarial dos professores. Nem mesmo os $7 \%$ que fora prometido cumpriria com o estabelecido no plano. Apesar de todas as problemáticas sofridas pelo plano, como o corte de metas de cunho econômico, considerada a meta base para realização das demais, o plano do governo 
foi "[...] a principal medida de política educacional decorrente da LDB" (SAVIANI, 1998, p. 3).

O processo de elaboração do plano sofreu diversas críticas em 1997 pela Associação Nacional de Pós-graduação e Pesquisa em Educação ANPEd, como uma das poucas instituições convocadas pelo poder executivo para fazer parte da discussão do PNE. Um plano extenso, com uma parte histórica vasta, com metas por modalidades de ensino, no total de 248 metas no projeto enviado ao Congresso Nacional em 12 de fevereiro de 1998 , apresentando ao País o que fora considerado pelo MEC como prioridade na educação brasileira.

A luta foi para garantir a implementação do que Saviani (1998, p. 161) considera meta das metas: o financiamento da educação. Pois, "[...] o aumento significativo e imediato dos recursos financeiros é posto como fator indispensável para o enfrentamento satisfatório dos problemas educacionais [...]". A fragilidade desse plano se deu pelo fato de o próprio governo insistir na impossibilidade de aumentar o financiamento para resolver a questão educacional no Brasil, apesar do governo ter apresentado, em 1998, um volume expressivo de arrecadação, de acordo com o Instituto Brasileiro de Geografia e Estatística - IBGE (SAVIANI, 1998).

Composta de extensas 81 páginas, a Lei n 10.172 aprovada em 9 de janeiro de 2001, mais de 4 anos depois da elaboração do projeto inicial, aprovada no Governo Fernando Henrique Cardoso, organizava o plano em diagnóstico, diretrizes, objetivos e metas, unificados com interdependência, para cada modalidade de ensino, desde a educação infantil até o nível superior, acrescentando para este último financiamento e gestão, contemplando também a valorização do magistério (BRASIL, 2009).

Quando o plano faz referência à participação, coloca apenas como uma função que deve ser exercida por um membro da comunidade escolar e na escola. A participação desse sujeito é restringida apenas ao âmbito escolar; não sinaliza para a participação dele na elaboração, acompanhamento e avaliação de políticas públicas educacionais porque 
para os formuladores de políticas educacionais não há espaço para esse tipo de participação como intervenção social (GRAMSCl, 1999).

O quadro abaixo apresenta a utilização do termo participação no Plano Nacional de Educação aprovado a partir da Lei n 10.172/2001.

Quadro 3 - O termo participação no texto do PNE (2001-2010)

\begin{tabular}{|c|c|c|}
\hline META & MODALIDADE & TRANSCRIÇÃO TEXTUAL \\
\hline Meta 9 & \multirow[b]{2}{*}{$\begin{array}{l}\text { Educação } \\
\text { infantil }\end{array}$} & $\begin{array}{l}\text { Promover a participação da comunidade na gestão } \\
\text { das escolas, universalizando, em dois anos, a instituição } \\
\text { de conselhos escolares ou órgãos equivalentes. }\end{array}$ \\
\hline Meta 16 & & $\begin{array}{l}\text { Implantar conselhos escolares e outras formas de } \\
\text { participação da comunidade escolar e local na } \\
\text { melhoria do funcionamento das instituições de } \\
\text { educação infantil e no enriquecimento das } \\
\text { oportunidades educativas e dos recursos } \\
\text { pedagógicos. }\end{array}$ \\
\hline Meta 9 & \multirow[t]{2}{*}{$\begin{array}{l}\text { Ensino } \\
\text { Fundamental }\end{array}$} & $\begin{array}{l}\text { Promover a participação da comunidade na gestão } \\
\text { das escolas, universalizando, em dois anos, a instituição } \\
\text { de conselhos escolares ou órgãos equivalentes. }\end{array}$ \\
\hline Meta 29 & & $\begin{array}{l}\text { Apoiar e incentivar as organizações estudantis, como } \\
\text { espaço de participação e exercício da cidadania. }\end{array}$ \\
\hline Meta 13 & \multirow[t]{2}{*}{ Ensino Médio } & $\begin{array}{l}\text { Criar mecanismos, como conselhos ou equivalentes, } \\
\text { para incentivar a participação da comunidade na } \\
\text { gestão, manutenção e melhoria das condições, de } \\
\text { funcionamento das escolas. }\end{array}$ \\
\hline Meta 18 & & $\begin{array}{l}\text { Apoiar e incentivar as organizações estudantis, como } \\
\text { espaço de participação e exercício da cidadania. }\end{array}$ \\
\hline Meta 18 & \multirow[t]{2}{*}{ Ensino Superior } & $\begin{array}{l}\text { Incentivar a generalização da prática da pesquisa } \\
\text { como elemento integrante e modernizador dos } \\
\text { processos de ensino-aprendizagem em toda a } \\
\text { educação superior, inclusive com a participação de } \\
\text { alunos no desenvolvimento da pesquisa. }\end{array}$ \\
\hline Meta 22 & & $\begin{array}{l}\text { Garantir a criação de conselhos com a participação } \\
\text { da comunidade e de entidades da sociedade civil } \\
\text { organizada, para acompanhamento e controle social } \\
\text { das atividades universitárias, com o objetivo de } \\
\text { assegurar o retomo à sociedade dos resultados das } \\
\text { pesquisas, do ensino e da extensão. }\end{array}$ \\
\hline Meta 22 & \multirow[b]{2}{*}{$\begin{array}{l}\text { Financiamento } \\
\text { e Gestão }\end{array}$} & $\begin{array}{l}\text { Definir, em cada sistema de ensino, normas de gestão } \\
\text { democrática do ensino público, com a participação } \\
\text { da comunidade. }\end{array}$ \\
\hline Meta 24 & & $\begin{array}{l}\text { Desenvolver padrão de gestão que tenha como } \\
\text { elementos a destinação de recursos para as atividades } \\
\text { fim, a descentralização, a autonomia da escola, a } \\
\text { equidade, o foco na aprendizagem dos alunos e a } \\
\text { participação da comunidade. }\end{array}$ \\
\hline
\end{tabular}

Fonte: PNE (2001-2010), Brasil, 2001. 
O conteúdo expresso nos documentos oficiais sempre mostra uma linguagem que se destina a exprimir os desejos, anseios dos projetos de quem o representa, é uma linguagem sempre intencional, carregada de sentidos. Nessa direção, pode ser percebido que o conteúdo presente no Plano, deixa claro como orientação institucional que a sociedade, aqui denominada, muitas vezes, de comunidade escolar, deve participar das ações da escola, principalmente nas modalidades da educação básica, porém não deixa específico como seria essa participação no ambiente escolar.

Aguiar (2010, p. 709) faz um alerta sobre a avaliação do PNE (2001-2010) feita pelos órgãos governamentais, mediante um novo plano que se despontava no cenário nacional, a partir do término do período de vigência do plano anterior, que esbarrava na ausência de neutralidade no processo de avaliação porque "[...] a avaliação de um plano educacional é realizada a partir de determinados valores e óticas, logo, não há neutralidade".

O Plano só terá coerência se para quem ele é destinado, a classe trabalhadora, tenha sua participação na elaboração e acompanhamento de suas metas. Nessa perspectiva, Arelaro (2007, p. 902) afirma que:

[...] as avaliações dos planos nacionais já elaboradas no Brasil - trienais quinquenais e decenais - explicitam que tais planos, a quase totalidade elaborada por especialistas ou tecnocratas sem contato com a realidade social, tiveram como objetivo maior o cumprimento de exigência burocrática, dispensando a participação dos grupos sociais que seriam atingidos por suas propostas, e, em função disso, acabaram se tornando "letra morta", pois ninguém se sentiu impelido ou comprometido a implementá-los.

A autora atenta para o fato de a participação da sociedade ser aclamada no cenário nacional com o objetivo de que a mesma sociedade se engaje no acompanhamento e monitoramento das metas e estratégias traçadas para a educação em um período de dez anos.

A crítica apontada tanto por Saviani (2007) quanto por Gadotti (2008) acerca do pouco interesse do governo na execução das metas do PNE 20012010, diz respeito ao investimento do governo federal para a execução das referidas metas, fazendo com que o plano não seja uma carta de intenção 
para a educação. O autor afirma que com a entrada do governo Lula, trouxe a crença popular de que os vetos seriam derrubados para que o plano, ao assumir o caráter de plano com orçamento viável para a execução, pudesse avançar. Porém isso não aconteceu, o que houve foi a ampliação do prazo de avaliação do plano para 2014, distanciando o próprio Partido dos Trabalhadores da base que o originou (SAVIANI, 2007).

Assim, diante do exposto e da percepção de que o PNE 2001-2010 não teve força para sair do papel e, finalizando o período de vigência, o novo PNE com vigência inicial de 2014 a 2024, iria tentar sanar os problemas que o primeiro PNE não conseguiu resolver. E um dos elementos colocados pela avaliação do PNE 2001-2010 foi a não participação da sociedade de forma efetiva na elaboração e acompanhamento das metas e estratégias do plano.

A seguir, discutiremos mais uma tentativa de participação da sociedade na elaboração do PNE com vigência para 2014-2024, tendo sido aprovado, também, de forma tardia, buscando analisar o conceito de participação empregado nesse plano, se foi uma continuidade do anterior ou teve alguma mudança significativa no tocante a participação da sociedade.

\section{O PLANO NACIONAL DE EDUCAÇÃO 2014-2024: A LUTA PELA PARTICIPAÇÃO DA SOCIEDADE NO PLANEJAMENTO DAS POLÍTICAS EDUCACIONAIS}

O Plano Nacional de Educação com vigência até 2010 estava chegando ao fim e metas que foram planejadas não conseguiram ser cumpridas em uma década, portanto era o momento de elaborar um novo Plano Nacional de Educação com vigência por mais dez anos, no intuito de tentar executar as ações não realizadas no plano anterior. Era mais fácil fazer um novo plano que responsabilizar os responsáveis pela sua execução.

No período entre 28 de março e 01 de abril de 2010, aconteceu a Conferência Nacional de Educação - CONAE, com o tema Construindo um Sistema Nacional Articulado de Educação: Plano Nacional de Educação, suas Diretrizes e Estratégias de Ação (OLIVEIRA, 2010), que teve como objetivo convocar a sociedade para participar das discussões e elaboração da proposta do novo PNE. 
A Secretaria de Articulação com os Sistemas de Ensino - SASE, criada desde 2011, a partir da Conferência Nacional de Educação (2010) com a proposta de prestar assistência técnica aos municípios no tocante ao monitoramento e avaliação dos planos, cujo slogan "para a educação melhorar, todos devem participar", tratou de orientar os municípios e estados como deveria ser organizada a elaboração do novo PNE.

A CONAE/2010 trouxe como tema central "Construindo o sistema nacional articulado de educação: o plano nacional de educação, diretrizes, estratégias de ação" (BRASIL, 2009, p. 3) e, logo em sua apresentação, conclama a necessidade de participação da sociedade e da articulação entre todos os entes federados. O próprio documento se intitula como espaço democrático em que as diversas opiniões serão respeitadas e todos os entes serão levados em consideração no final desse planejamento sobre a educação no Brasil. Quando o documento traz como orientação "[...] manter constante o debate nacional, orientando a mobilização nacional pela qualidade e valorização da educação básica e superior" (BRASIL, 2009, p. 7), as conferências municipais e estaduais deveriam ser realizadas para contemplar esse espaço de debate nacional.

Segundo Bodião (2016) foram percebidas contradições na elaboração dos documentos de referência que serviriam de base para o plano, desde a Conferência Nacional de Educação - CONAE de 2010, em que as propostas enviadas pela sociedade não chegaram ao documento final. O documento final foi estruturado em três eixos: "a) a educação como direito individual; b) a educação como fator de desenvolvimento econômico e social; c) a educação como meio de combate à pobreza" (AGUIAR, 2010, p. 710).

Nessa direção, cabe analisar que a concepção de participação na perspectiva do governo resume apenas a presença da sociedade nos espaços de debate para fomentar a discussão.

A CONAE 2010 tornou-se um espaço de debates sobre a organização futura da educação no Brasil. Como o PNE de 2001-2010 não conseguiu ser exequível em suas propostas por conta de várias contradições e percalços. $\mathrm{Na}$ fase de formulação do novo plano, o governo precisou levar em 
consideração a realidade atual e a participação da mesma na fase de elaboração. Apesar de que suas intenções não correspondiam às intenções da sociedade como ficou esclarecido a partir do novo plano aprovado.

O Plano Nacional de Educação vigente sofreu um lapso temporal de quase quatro anos de atraso, depois do fim do prazo de vigência do plano anterior. Esse atraso se deve às disputas de interesse de grupos econômicos que divergiam sobre o aumento do PIB de $7 \%$ para $10 \%$.

O período que discorreu entre os anos em que o país ficou sem um plano de educação de 2011 a 2014, foi um período conturbado e de instabilidade decorrente da mudança de governo em que Dilma Rousself (PT) assumiu o governo como presidente. Somente no ano de 2014 houve a aprovação da Lei $n^{\circ} 13.005$ em 25 de julho de 2014, dando legalidade ao novo Plano Nacional de Educação para o decênio 2014-2024.

Ao contrário do que aconteceu no PNE 2001-2010, o qual sofreu vetos na parte do financiamento, no PNE 2014-2024, a sociedade se organizou para exigir a execução dos $10 \%$ do PIB que deveria ser destinados à educação pública, apesar de a correlação de forças entre legisladores e governo tenha atrasado ainda mais a aprovação do Projeto de Lei (FERREIRA, 2013).

No novo plano, coube ao Ministério da Educação apoiar estados e municípios na elaboração participativa da sociedade (LOUREIRO, 2016). O desafio para estados e municípios foi garantir a participação da sociedade na elaboração dos seus respectivos planos como orientado pelas diretrizes do PNE nos cadernos de orientação para a elaboração do PNE. A necessidade de elaboração de um plano de educação que fosse exequível e tivesse sucesso, além do financiamento para a execução das ações, precisaria também da participação da sociedade na construção do documento, de modo a representar os anseios da sociedade.

Atento à problemática de que a existência de duas propostas, da sociedade e do governo, não encontra espaço no projeto de sociedade estabelecido pelo governo, pelo fato de ser o governo o financiador das políticas educacionais, a proposta da sociedade só adquire espaço na 
proposta do governo se essa não for de encontro com o projeto do governo, o que é inviável na disputa de interesses do sistema capitalista.

As políticas públicas são resultado de debates que buscam cobrar do Estado sua responsabilidade na garantia dos direitos sociais. São tratadas por diversos autores (AZEVEDO, 1997; GHANEM, 2004; GOMES, 2011; SANTOS, 2011) como espaço de aprendizagem da democracia, espaço esse que, também, pode ser utilizado pela sociedade através da participação como um espaço de modificação da realidade social.

A política educacional busca organizar o modelo educacional que deve ser seguido no Brasil e acaba por atender aos interesses de seus formuladores.

Azevedo (1997, p. 59) define o conceito de política educacional "[...] como programa de ações construídas também para atender objetivos e decisões políticas que se realiza por meio do Estado e se materializa nos espaços educacionais".

A autora também aponta para o fato das políticas públicas voltadas para a educação que se materializam por meio de legislação, programas e projetos destinados a modernizar a educação e garantir assim a hegemonia como soberania da vontade do Estado.

É fato que a participação da sociedade na elaboração dos Planos de Educação é de suma importância, mas é necessário analisar e refletir que tipo de participação ambos pleiteia, visto que, os condicionantes da participação como: a prevalência de interesses particulares de grupos econômicos e políticos sobre interesses públicos, ausência de estrutura histórico-cultural na formação do sujeito, ausência de consciência de classe, dentre outras, considerando que "[...] a participação não deve ser estudada sem referência ao conflito social" (BORDENAVE, 1994, p. 41), interferem e marcam a luta de interesses.

O conceito de participação não deve se resumir apenas em presença; é preciso ter uma abrangência no sentido que o autor coloca, de fazer parte, de ser parte de algo. 
Atualmente, essa vontade em participar está ficando cada vez mais necessária pelo fato de a sociedade brasileira estar passando por momentos difíceis de cerceamento da participação.

O que impediria a sociedade de participar? A aproximação dos interesses pessoais segundo Patemam (1992, p. 44-45) porque:

[...] quando o indivíduo se ocupa somente de seus assuntos privados, argumenta, e não participa das questões públicas, sua auto-estima é afetada, assim como permanecem sem desenvolvimento suas capacidades para uma ação pública responsável.

A autora mostra que enquanto o indivíduo estiver preocupado com interesses particulares, ao fixar sua atenção apenas em si, irá se afastando dos interesses públicos.

A participação da sociedade na elaboração de políticas educacionais, em que ela apenas comparece e não consegue dar suas opiniões, acaba por sendo um instrumento de figuração na execução das propostas governamentais com a legitimação e permissão da sociedade para sua efetivação "numa cultura de governo patrimonialista, com as políticas educacionais ditadas pela elite, associada a alta rotatividade, [que] explica a interrupção e abandono dos planos de educação" (BORDIGNON, 201 1, p. 29) e interrompe a luta por uma educação de qualidade.

A educação de qualidade deve ser uma educação que contribua para a equidade e garanta a eficiência dos recursos voltados à educação (DOURADO, 2007), mesmo enfrentando o paradoxo de uma estrutura social pautada na desigualdade proveniente do capitalismo que negligencia a qualidade em todos os espaços sociais, impedindo a possibilidade da existência da ideia de qualidade e equidade numa sociedade desigual.

Dessa forma, o planejamento educacional perde o status de conciliação da "[...] ideia de democracia, via participação dos segmentos sociais" (FERREIRA, 2013, p. 58) e assume, a partir da centralidade do Estado, o papel de legitimar os interesses privados sobre as necessidades da coletividade. 
A relação que se estabelece entre o planejamento e a racionalidade hegemônica remete ao fato de o planejamento tornar-se 0 instrumento utilizado para consolidar as ações de um projeto de governo, visto que "[...] no planejamento há uma decisão política de controle social" (FERREIRA, 2013, p. 66).

A estrutura do Plano Nacional, aprovado sob a Lei n ${ }^{\circ} 13.005 / 2014$, surge de forma condensada e distribuída em quatorze artigos e um anexo que apresenta o conjunto de vinte metas com suas respectivas estratégias de desenvolvimento. Abandona o formato extenso do antecessor, com um referencial histórico abrangente e se restringe de forma similar através das suas diretrizes o que fora expresso no art. 214 da Constituição Federal.

As metas fazem referência aos três níveis de ensino (Fundamental, Médio e Superior), incluindo a Educação Infantil como parte da educação básica, como também dispensa atenção para as modalidades de ensino, desde a Educação de Jovens e Adultos até a Educação Profissional. Quanto a presença da sociedade, o plano traz em sua estrutura organizativa dezoito vezes o termo participação de forma semelhante ao plano anterior, e deixa acordado como será definida essa forma de organização da sociedade para garanti-la.

É necessária a reflexão sobre para que de fato os fóruns de educação foram instituídos, porque o que está posto de forma visível nem sempre é o que invisivelmente compõem a intencionalidade (MINAYO, 2007). O PNE 20142024 apresenta no inciso IV, do parágrafo $2^{\circ}$ do art. $8^{\circ}$ como deveria ter sido a participação da sociedade no Plano de Educação.

O quadro a seguir mostra como o termo participação foi utilizado pelos redatores do texto que deu origem ao PNE para o decênio 2014-2024. 
Quadro 4 - A presença do termo participação no PNE 2014-2024

\begin{tabular}{|c|c|c|}
\hline META & MODALIDADE & TRANSCRIÇÃO TEXTUAL \\
\hline Meta 2 & $\begin{array}{l}\text { Ensino } \\
\text { Fundamental }\end{array}$ & $\begin{array}{l}\text { Incentivar a participação dos pais ou responsáveis no } \\
\text { acompanhamento das atividades escolares dos filhos } \\
\text { por meio do estreitamento das relações entre as } \\
\text { escolas e as famílias; }\end{array}$ \\
\hline Meta 3 & Ensino Médio & $\begin{array}{l}\text { Estimular a participação dos adolescentes nos cursos } \\
\text { das áreas tecnológicas e científicas; }\end{array}$ \\
\hline Meta 4 & $\begin{array}{c}\text { Educação } \\
\text { Especial }\end{array}$ & $\begin{array}{l}\text { Promover parcerias com instituições comunitárias, } \\
\text { confessionais ou filantrópicas sem fins lucrativos, } \\
\text { conveniadas com o poder público, a fim de favorecer } \\
\text { a participação das famílias e da sociedade na } \\
\text { construção do sistema educacional inclusivo; }\end{array}$ \\
\hline \multirow{3}{*}{ Meta 7} & \multirow{3}{*}{ IDEB } & $\begin{array}{l}\text { Apoiar técnica e financeiramente a gestão escolar } \\
\text { mediante transferência direta de recursos financeiros à } \\
\text { escola, garantindo a participação da comunidade } \\
\text { escolar no planejamento e na aplicação dos recursos, } \\
\text { visando à ampliação da transparência e ao efetivo } \\
\text { desenvolvimento da gestão democrática; }\end{array}$ \\
\hline & & $\begin{array}{l}\text { Consolidar a educação escolar no campo de } \\
\text { populações tradicionais, de populações itinerantes e } \\
\text { de comunidades indígenas e quilombolas, respeitando } \\
\text { a articulação entre os ambientes escolares e } \\
\text { comunitários e garantindo: o desenvolvimento } \\
\text { sustentável e preservação da identidade cultural; a } \\
\text { participação da comunidade na definição do modelo } \\
\text { de organização pedagógica e de gestão das } \\
\text { instituições, consideradas as práticas socioculturais e as } \\
\text { formas particulares de organização do tempo; }\end{array}$ \\
\hline & & $\begin{array}{l}\text { Fortalecer, com a colaboração técnica e financeira } \\
\text { da União, em articulação com o sistema nacional de } \\
\text { avaliação, os sistemas estaduais de avaliação da } \\
\text { educação básica, com participação, por adesão, das } \\
\text { redes municipais de ensino, para orientar as políticas } \\
\text { públicas e as práticas pedagógicas, com o } \\
\text { fornecimento das informações às escolas e à } \\
\text { sociedade; }\end{array}$ \\
\hline $\begin{array}{c}\text { Meta } \\
12\end{array}$ & $\begin{array}{c}\text { Educação } \\
\text { Superior }\end{array}$ & $\begin{array}{l}\text { Ampliar a participação proporcional de grupos } \\
\text { historicamente desfavorecidos na educação superior, } \\
\text { inclusive mediante a adoção de políticas afirmativas, } \\
\text { na forma da lei; }\end{array}$ \\
\hline $\begin{array}{c}\text { Meta } \\
13\end{array}$ & $\begin{array}{l}\text { Educação } \\
\text { Superior }\end{array}$ & $\begin{array}{l}\text { Induzir processo contínuo de autoavaliação das } \\
\text { instituições de educação superior, fortalecendo a } \\
\text { participação das comissões próprias de avaliação, } \\
\text { bem como a aplicação de instrumentos de avaliação } \\
\text { que orientem as dimensões a serem fortalecidas, } \\
\text { destacando-se a qualificação e a dedicação do } \\
\text { corpo docente; }\end{array}$ \\
\hline
\end{tabular}




\begin{tabular}{|c|c|c|}
\hline $\begin{array}{c}\text { Meta } \\
14\end{array}$ & Pós-graduação & $\begin{array}{l}\text { Estimular a participação das mulheres nos cursos de } \\
\text { pós-graduação stricto sensu, em particular aqueles } \\
\text { ligados às áreas de Engenharia, Matemática, Física, } \\
\text { Química, Informática e outros no campo das ciências; }\end{array}$ \\
\hline \multirow{3}{*}{$\begin{array}{c}\text { Meta } \\
19\end{array}$} & \multirow{3}{*}{$\begin{array}{c}\text { Gestão } \\
\text { Democrática }\end{array}$} & $\begin{array}{l}\text { Priorizar o repasse de transferências voluntárias da } \\
\text { União na área da educação para os entes federados } \\
\text { que tenham aprovado legislação específica que } \\
\text { regulamente a matéria na área de sua abrangência, } \\
\text { respeitando-se a legislação nacional, e que considere, } \\
\text { conjuntamente, para a nomeação dos diretores e } \\
\text { diretoras de escola, critérios técnicos de mérito e } \\
\text { desempenho, bem como a participação da } \\
\text { comunidade escolar; }\end{array}$ \\
\hline & & $\begin{array}{l}\text { Estimular a constituição e o fortalecimento de } \\
\text { conselhos escolares e conselhos municipais de } \\
\text { educação, como instrumentos de participação e } \\
\text { fiscalização na gestão escolar e educacional, inclusive } \\
\text { por meio de programas de formação de conselheiros, } \\
\text { assegurando-se condições de funcionamento } \\
\text { autônomo; }\end{array}$ \\
\hline & & $\begin{array}{l}\text { Estimular a participação e a consulta de profissionais } \\
\text { da educação, alunos (as) e seus familiares na } \\
\text { formulação dos projetos político-pedagógicos, } \\
\text { currículos escolares, planos de gestão escolar e } \\
\text { regimentos escolares, assegurando a participação dos } \\
\text { pais na avaliação de docentes e gestores escolares. }\end{array}$ \\
\hline
\end{tabular}

Fonte: PNE (2014-2024), Brasil, 2014.

No tocante à concepção de participação é que a mesma continua sendo posta de forma restrita ao espaço escolar por meio da presença dos pais no acompanhamento de atividades escolares, um dos segmentos da escola com menor presença e atuação no ambiente escolar. Os pais não participam porque ainda não perceberam a importância que sua presença atuante tem no espaço educacional (LÜCK, 2010).

O quadro também aponta a participação de forma ampla, nas questões educacionais, como a participação da família na elaboração do sistema educacional inclusivo sem levar em consideração o fato de que a grande maioria dos pais dos alunos das escolas públicas não serem incluídos por parte da desigualdade acirrada em que está mergulhada a classe pobre.

A sociedade é convocada para opinar no modelo de política pública, como se isso fosse possível diante de toda falta de condições que a impedem 
de atuar. A discussão é direcionada pelos órgãos reguladores para que a intervenção da sociedade seja de forma limitada dentro das normas dos governos (SAES, 2003), até porque essas discussões não estarão presentes na produção final dos documentos oficiais.

Apesar da palavra participação se apresentar com mais frequência no plano de 2001 (32 vezes), a concepção de uma participação ampliada da comunidade na elaboração de políticas educacionais surge com ênfase no PNE de 2014.

Quadro 5 - Quantitativo do termo participação existente nos Planos Nacionais de Educação

\begin{tabular}{|c|c|}
\hline PNE 2001-2010 & PNE 2014-2024 \\
\hline 32 vezes & 19 vezes \\
\hline
\end{tabular}

Fonte: Dados da pesquisa, 2019.

Percebeu-se que o discurso do governo parte do conceito de participação baseado na presença do sujeito nos espaços de deliberação, porém o governo parte da ideia de participação como um instrumento necessário à legitimação das propostas governamentais. Ele não nega a necessidade de representação da sociedade nos espaços de debate, mas há um grande distanciamento entre os desejos da sociedade e a presença deles nos textos finais dos documentos oficiais.

Em uma sociedade em que a participação direta virou a exceção à regra (BOBBIO, 2000), como alardear nos discursos que as políticas educacionais, no caso do PNE, foram elaboradas com a participação da sociedade? E que tipo de participação é essa vista nos documentos oficiais? Uma participação relacionada com a presença?

O artigo sinaliza para a necessidade de aprofundamento nos debates sobre a participação da sociedade nos espaços de decisão como forma de intervenção na realidade social, porque como foi verificado existe um conflito de interesse presente a partir dos documentos oficiais em que há divergência na concepção de participação através das convocatórias da sociedade 
para fazer-se presente nos espaços de deliberação e o desejo da sociedade em intervir na realidade social sem instrumentalização necessária para atuar de forma a contribuir com a realidade local.

\section{CONSIDERAÇÕES FINAIS}

O artigo buscou analisar, a partir do texto dos documentos que deram origem ao Plano Nacional de Educação (2001-2011/2014-2021) se a concepção de participação empregada nos documentos oficiais, estava ancorada na concepção de participação como intervenção social ou se apenas foi considerada a partir da presença da sociedade como instrumento de legitimação e consolidação de projetos de governos.

Nessa trajetória, a pesquisa constatou que o modelo de participação vigente está alicerçado na ausência de condições para que o sujeito possa fazer debates e intervenções, falta de conhecimento da sociedade sobre a temática abordada, ausência de elementos de uma cultura participativa, distanciamento dos interesses coletivos, persistência dos governos em garantir a presença da sociedade apenas para legitimar suas propostas e presença de elementos que atuam de forma direta na ausência da sociedade nos espaços de decisão, como a recusa das pessoas em ser indicadas pelas suas respectivas instituições e atuação fragilizada dos que se apresentam quando convocados.

A análise revelou que os grupos que representam as classes que detêm o poder induzem, de forma efetiva, a sociedade a participar apenas como representantes dela na legitimação de interesses materializados nos projetos de governo, retirando da sociedade sua força política quando não oferece as mesmas condições que garantam uma atuação eficaz.

A participação requer do sujeito responsabilidade e envolvimento, que se tornam elementos essenciais para a elaboração do planejamento educacional como instrumento de modificação da realidade social.

E responsabilidade se adquire participando. O desconhecimento da realidade obriga o sujeito a uma limitação ou ausência de participação no planejamento em geral, como também no planejamento educacional. E esse 
desconhecimento da realidade juntamente com o assistencialismo leva o sujeito ao distanciamento da experiência democrática, porque "o mecanismo de inversão que transforma a realidade em ilusão ou a ilusão em realidade" (RANCIÈRE, 2013, p. 34) acaba por contribuir com esse distanciamento.

O sujeito necessita de experiências que o levem a querer tomar partido das situações do cotidiano, a ser parte das decisões como proposta de modificação dos problemas sociais, assim terá condições de intervir na realidade.

\section{REFERÊNCIAS}

AGUIAR, M. A. da S. Avaliação do Plano Nacional de Educação 2001-2009: questões para reflexão. Educação \& Sociedade, v. 31, p. 707-727, 2010.

AZEVEDO, J. M. L. de. A educação como política pública. Campinas, São Paulo: Autores Associados, 1997.

BENEVIDES, M. V. de M. Cidadania e direitos humanos. IEA. 2009. Disponível em: www.iea.usp.br/artigos. Acesso em: 31 jul. 2019.

BOBBIO, N. Teoria Geral da Política: a filosofia política e as lições dos clássicos. Rio de Janeiro: Elsevier, 2000.

BORDENAVE, J. E. D. O que é participação. 8. ed. São Paulo: Brasiliense, 1994.

BORDIGNON, G. et al. O planejamento educacional no Brasil. Brasília. Fórum Nacional de Educação. 2011 . Disponível em:

http://fne.mec.gov.br/images/pdf/planejamento_educacional_brasil.pdf. Acesso em: jun. 2018.

BRASIL. Lei $n^{\circ}$ 13.005, de 25 de junho de 2014. Aprova o Plano Nacional de Educação (PNE) e dá outras providências. Diário Oficial da União [da] República Federativa do Brasil, Brasília, 2014. Disponível em: http://www.planalto.gov.br/ccivil_03/_ato2011-2014/2014/lei/l13005.htm. Acesso em: 21 ago. 2018.

BRASIL. Ministério da Educação (MEC). CONAE 2010. Construindo o Sistema Nacional Articulado de Educação: o plano nacional de educação, suas diretrizes e estratégias de ação. Documento Referência. Brasília: MEC, 2009.

BRASIL. Ministério da Educação. O PNE 2011-2020: Metas e Estratégias. 2011. Disponível em: 
http://fne.mec.gov.br/images/pdf/notas_tecnicas_pne_2011_2020.pdf. Acesso em: 02 de nov. 2018.

BRUEL, A. L. de O. Políticas e legislação da educação básica no Brasil. Curitiba: InterSaberes, 2012.

DOURADO, L. F. (org.). A qualidade da educação: conceitos e definições. Brasília: INEP/MEC, 2007.

FERREIRA, E. B. Democracia e tecnocracia no planejamento educacional brasileiro: tensões permanentes na educação do século 21. In: FERREIRA, E. B.; FONSECA, M. (org.). Política e planejamento educacional no Brasil do século 21. Brasília: Liber Livro, 2013.

GADOTTI, M. Convocados, uma vez mais: rupturas, continuidade e desafios do PDE. São Paulo: Instituto Paulo Freire, 2008.

GANDIN, D. A posição do planejamento participativo entre as ferramentas de intervenção na realidade. Currículo sem fronteiras. v. 1, n. 1, p. 81-95, Jan./Jun. 2001.

GHANEM, E. Educação escolar e democracia no Brasil. Belo Horizonte: Autêntica, 2004.

GOMES, A. M. Políticas públicas, discurso e educação. In: GOMES, A. M. (org.). Políticas públicas e gestão da educação. Campinas, São Paulo: Mercado das letras, 2011.

GRAMSCl, A. Cadernos do cárcere. Volume 1, $3^{\mathrm{a}}$ ed. Rio de Janeiro: Editora Civilização Brasileira, 1999.

LOUREIRO, W. N. Os planos de educação: estadual e municipal. In: OLIVEIRA, J. F. de; AGUIAR, M. A. da S. (orgs.). Planos de educação e ações articuladas. Camaragibe, PE: CCS gráfica e editora, 2016.

LÜCK, H. Gestão educacional: uma questão paradigmática. 5. ed. Petrópolis, RJ: Vozes, 2010.

MINAYO, M. C. de S. O Desafio do Conhecimento: Pesquisa Qualitativa em Saúde. 10. ed. São Paulo: HUCITEC, 2007.

OLIVEIRA, J. F. de. A educação básica e o PNE/201 1-2020: Políticas de avaliação democrática. Retratos da Escola, Brasília, v. 4, n. 6, p. 91-108, jan./jun. 2010.

RANCIÈRE, J. O mestre ignorante: cinco lições sobre emancipação intelectual. 3. ed. Belo Horizonte: Autêntica, 2013. 
SAES, D. A. M. de. Cidadania e capitalismo: uma crítica à concepção liberal de cidadania. Crítica Marxista. n 16. Campinas, SP: Revan, 2003. p. 9-56.

SANTOS, A. L. F. dos. Gestão democrática da escola: bases epistemológicas, políticas e pedagógicas. In: GOMES, A. M. (org.). Políticas públicas e gestão da educação. Campinas, São Paulo: Mercado das letras, 2011.

SAVIANI, D. Da nova LDB ao novo plano nacional de educação: por uma outra política educacional. Campinas: Autores Associados, 1998.

SAVIANI, D. O plano de desenvolvimento da educação: análise do projeto do MEC. Educ. Soc., Campinas, vol. 28, n. 100 - Especial, p. 1231-1255, out. 2007.

TEODORA, R.; COSTA, C. S. da; BUENO, E. D. de L.; NAGEL, J. S. de O. Política Educacional: participação democrática no plano municipal de educação de Curitiba. Interações. Mato Grosso do Sul, v. 12, n. 40, p. 89-109, 2016.

VALENTE, I.; ROMANO, R. PNE: Plano Nacional de Educação ou carta de intenção? Educação \& Sociedade, Campinas, v. 23, n. 80, p. 96-107, set./2002.

Recebido em: 03 de julho de 2021. Aprovado em: 19 de outubro de 2021.

Publicado em: 27 de janeiro de 2021. 